\title{
Traditional and Alternative Approaches to the Method of Situational Analysis in Russia: Evidence from the Case Study "Istanbul in the Life and Works of Martiros Saryan"
}

\author{
Olga Fedotova ${ }^{1}$, Pavel Ermakov ${ }^{2}$, Vladimir Latun ${ }^{3}$, Haykaz Hovhannisyan ${ }^{4}$, Grant Avanesyan $^{5}$
}

\begin{abstract}
The article analyzes the transformation of the methodological toolkit for teaching humanities and sciences in the Russian Federation. The method of case study, being widely spread in modern higher education research, is used as an example to illustrate the attempts to implement the best practices of foreign educational technology into tertiary academic process in Russia. The authors provide some historical aspects of introducing case studies in modern teaching practice. The article features peculiarities of the Soviet approach to the structure of cases. Content analysis helps to identify similarities and differences in Soviet/post-Soviet approaches to case study construction and brings into focus the problem points which reveal misinterpretation and/or misuse of didactic materials designated as cases. The approach suggested in the article implies presenting the content of a case study as a collection of documents related to a certain topic. The case study "Istanbul in the life and work of the artist Martiros Saryan" demonstrates that a case can have invariable and variable parts to reflect the specificity of the didactic task within the discipline. Such approach is expected to support students' cognitive activity, develop creativity in searching additional sources and missing materials, improve efficiency of students' autonomous work on solving complex problem solution.
\end{abstract}

Keywords:. case study, transformation, alternative approach, teaching problem books, didactic task, Martiros Saryan, Istanbul.

\section{Introduction}

Recent social and economic changes in Russia entail a reassessment of many aspects in terms of worldview and theoretical-cognitive consideration of such issues as shaping person's identity and preparing for life in a multidimensional knowledge-based globalizing society (Draskovic et al., 2017). Training of competent specialists involves expanding their expertise in a range of situations: solving non-standard professional problems; finding the best ways of

\footnotetext{
${ }^{1}$ Prof., Doctor of Pedagogy, Head of the Department, Southern Federal University, fod1953@yandex.ru

${ }^{2}$ Academician, Prof., Doctor of Biology, Head of the Department, Southern Federal University, paver@sfedu.ru

${ }^{3}$ Assoc. Prof., Candidate of Geography, Head of the Department, Southern Federal University, vlatun@yandex.ru

${ }^{4}$ Prof., Doctor of History, Yerevan State University, haykazh@ mail.ru

${ }^{5}$ Prof., Doctor of Psychology, Head of the Department, Yerevan State University, avanesyang@mail.ru
} 
resolving work-related conflicts; studying, understanding, and explaining the phenomena of the surrounding reality, building awareness of their nature, causes and interplay. An important role is played by the specialist's willingness and ability to address professional challenges pro-actively, taking into account specific circumstances deduced from the factual information. In this regard modern education is polyparadigmatical. Class and lesson based teaching methods which are typical of the traditional system (lectures, seminars, workshops etc.) have been the leading forms of education in the Russian higher school since the $17^{\text {th }}$ century. At the same time, there have been attempts to modernize the system of higher education teaching methods, to adopt the best foreign practices and technologies.

Case-study technology is one of the most effective methods, though not widely used in Russian professional education system yet. Meanwhile, it gives an opportunity for purposeful cultivation of such professionally relevant characteristics, as pro-active ability to pinpoint the areas of concern in professional practice, to perform risk analysis procedure and diagnose the problem situation, to articulate one's professional stance and to communicate it to the audience. Nevertheless, the system of higher professional education retains certain inertia and conservatism in using qualification-based approach in choosing the system of teaching methods. It tends to follow the algorithm of knowledge reproduction. Thus, there is an instant need of cultivating specific competencies required for successful professional activity of a specialist, regardless of their field of knowledge. These competencies involve diagnosis, forecasting, strategic planning, analytical components in professional activities. The purpose of the article is to feature the scope of approaches to the method of case study in Soviet and post-Soviet period, to outline the ways of using its latent didactic potential in the system of teaching disciplines of the humanities.

\section{Literature Review}

\section{Historical background of the research}

In the modern educational theory case-study is understood as the method of analyzing particular situations. According to Hancock D.R. (2006), the term hadn't been used in educational context until 1870, when the law school at Harvard University first applied a new approach to consider complicated cases of legal practice (Mauch \& Tarman, 2016). The systematic use of case-study method at the university started in the 1930-s. Sets of business cases are found in the reports of Harvard University dated 1925. The method gradually won great popularity in the systems of higher education of other countries. In 1973, 22 higher education 
institutions initiated the establishment of non-profit organization «The Case Clearing House Of Great Britain and Ireland» to create conducive environment facilitating exchange of case materials between university professors. In 1974 the organization was officially recognized as a charitable organization. After being renamed European Case Clearing House (ECCH) in 1991, it took the lead in producing, collecting and distributing cases within the European education space and beyond. In 1992, the organization opened its office in Babson College (USA), which has gained worldwide fame as an educational institution that implements innovative entrepreneurship programs to promote leadership in changing global environment and to make leaders able to anticipate, initiate and manage changes. Currently ECCH is an International organization with two headquarters: based at Babson College (Massachusetts, USA), and Cranfield University (Cranfield, United Kingdom). The office in Babson College is geared toward working with North American colleagues, while Cranfield University caters for European, African, Asian, Australian and South American members of the organization and commercial clients. ECCH unites more than 500 institutions and corporate members around the world and has a collection of over 38,500 cases on business and management issues, among which 1,400 cases are written in languages other than English. In German-speaking countries the term "Fallstudie" is used where "Fall" is the case, and "Studie" is the study.

The case study technology hasn't been known in Russia until recently. So far, no specific efforts have been made to introduce its elements into the learning policy of higher education establishments. However, the analysis of primary sources suggests that the methodological system of the national higher school is being updated in terms of components of case-based learning. As part of the thesis research project, Shumova I.V. (2010) studied the use of casestudy methods in teaching internship for undergraduate Philology students. The use of virtual case-study technologies for promoting learning autonomy of students of the Ministry of Emergency Situations was the subject of D.A. Eliseev's research (2010). E.N. Krasikova (2009) studied the use of case technologies for developing method competence in linguistics teachers. Issues of instrumental support of online teaching technology for computer science were considered in the dissertation research by V.V. Bovt (2005). Issues related to the use of case study in strategic management training were dealt with by E.V. Egorova (2008). Over the last years the issue was given increased attention in a number of $\mathrm{PhD}$ thesis (Gadikurbanova, 2015, Zubova, 2015, Naumova, 2014, Tulepbergenova, 2015), research papers (Nadarajah et al., 2010, 
Tunstall \& Lynch, 2010, Baumgartner \& Shankararaman, 2015, Aktan, 2016, Hedden, 2017) and textbooks (Situational analysis or the anatomy of case study method, 2002. The understanding of the case study method can vary. To sum up, the main points of the issue interpretation approaches should be determined. This is the method of specific situation analysis which is related to the non-game methods of active situation and problem-based learning; intensive training of learners which allows for appropriate solution of the problem (mainly the Harvard School); prepared situational training, broadening the students' professional perspectives; setting the problem in a specific way so that the solution of the problem should be based on the analysis of the documentary sources that involves using a wide range of professional knowledge, as well as certain principles of professional and critical thinking (Manchester School); method of detailed analysis of events, personal or group behavior as a model of a specific medical, psychiatric, mental or social phenomenon (Smolyaninova, 2000); not only a faithful description of non-standard events, but a whole complex of information necessary to give an assessment to a specific situation and suggest the ways out (Eliseev, 2010).

Case study method in the history of Russian education.

It should be noted that the history of Russian education the term "casus method" was used alongside with "case study". Having studied the publications of Harvard Business Review (Harvard University Authority), Soviet ideologists saw education potential of the case study method and recommended it as a teaching technique in party schools. In the 1930-s and 1940-s Soviet party schools were actively searching for new techniques to train skilled economists within a short period of time (Kasitsky, 1948, The main production issues in the program of the initial party school of the mine, 1931). Analyzing specific situations made it possible to train the party executives who could deal effectively with economic and ideological problems in the country's challenging socioeconomic environment.

Developing contacts across international borders and the evidence for the case-study teaching method fueled the interest of Russian teachers and encouraged them to develop teaching guidelines for the method. The methodology was used in the Soviet teacher training system, with the emphasis on the theory of the learning policy within the education science discipline, whereas the demand for practical problem solving training was still being felt. There were socalled "teaching problem books" published in the 1960-s and later. They were describing very briefly (Savelyeva, 2013), or quite at length and in many details (Kulyutkin \& Sukhobskaya, 
1981, Smoylaninova, 2000, Fedotova, 2007), some cases ("problems"). The learners were supposed to find a way out ("problem solution"). The list of keys for self-check could be found at the end of the book, where the authors provided the learners with the single correct answer to each problem, appropriate in terms of Marxist-Leninist education theory. In the post-Soviet period the teaching potential of the case-study method also attracted attention of the scholars (Spirin et al., 1991). However, it should be noted that the representatives of the post-Soviet scholarly traditions shared one view on the case-study method as a distinctive analytical technology adding to the learners' experience or real life problem solving, where the problem is presented in a set of documents and materials. Growing popularity of the case-method and the spread of the "case" concept clouded the issue of selecting proper didactic materials as the concept is mentioned in the titles. The examples are as follows:

1. The book "Finance. The didactic complex (case) for students on specialty 080105 "Finance and credit" (Kostryukova, 2006) does not contain the case, as it is claimed in the title. Instead, it gives fragments of the State educational standard, the symmabi of the discipline, the course schedule, lesson plans, etc. (Kostryukova, 2006). It does not provide a single example of a problem-based situation to be resolved by students. The same approach is seen in other books published by the Chelyabinsk branch of the Russian State University of Trade and Economics (Volostnikova, 2005a, 2005b).

2. The author of "Econometrics. Basic concepts and formulas: a short course of case studies for correspondence students of specialties 060400 "Finance and credit" (Vlasov, 2004) provides the readers instead of the promised text of the case study lecture, with formulas for pair regression and correlation, time series in econometric studies, etc., that is, materials that are not connected in any way with the process of finding solution to a real-life precedent.

This poses an obvious question of whether the teaching approaches to case-study in education have transformed over time. Some clarification can be given by the empirical study.

\section{Methodological Framework}

The study was conducted in two stages in accordance with the tasks and hypotheses put forward.

Hypothesis of the study. The transformation of the method of situational analysis can be traced through the changes of its structure and structural principles of the cases. 
The source of the study is a collection of cases, titled according to the thematic content (a total of 24 cases). The choice of this source is explained by the fact that the author claims the approach to be new, and suggests a methodology for case design and use (Savelyeva, 2013).

The study methods are content analysis and comparative analysis (Fedotova \& Chigisheva, 2015), interpretation of the results. The meaningful category of the analysis is a teaching case, with the sentences of the case explanation being takes as units of account. After the units from various structural components of the text were counted, the figures were grouped into EXCEL code tables. They served as the database for the graphs to visualize the analysis results.

\section{Results and Discussion}

The case study can be of different structure. As it was noted above, in Soviet times the teaching problem consisted of two structural components: description of the situation and the question for the learner to answer. New components were added to educational and research cases in post-Soviet period, such as: "visiting card", "situation explanation", "case problem", "task" (Fedotova, 2007).

Analysis of the case studies showed that they contain two structural components: the text describing the situation and the task. Their correlation is seen on Fig. 1.

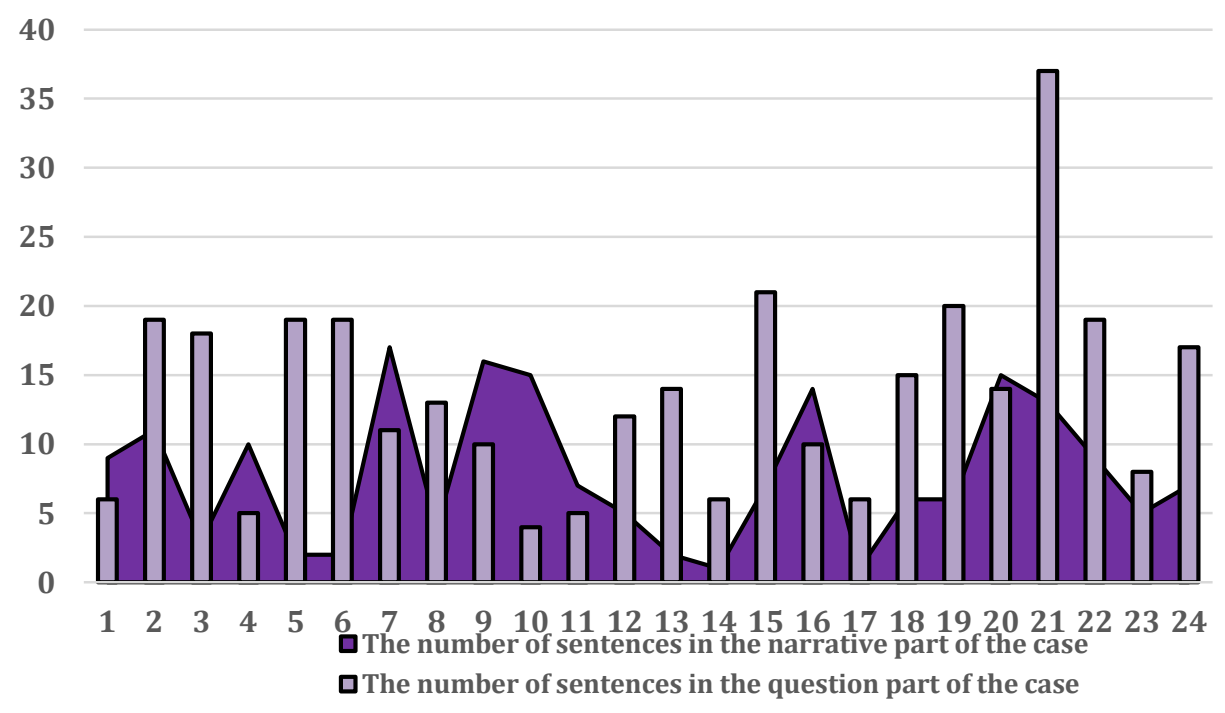

Figure 1. The number of sentences in the text of the case description and the task explanation. 
As is seen from the bar diagram, the total volume of the tasks (254 sentences) exceeds the total volume of the information part of the case describing the problem situation (175 sentences). The amount of the text presenting the task of the case is quite significant.

It should be noted that the task explaining part of the text contains both declarative and interrogative sentences. We consider the ratio of declarative sentences with focus on informing and/or clarifying and the part of the text with the task explanation. The data are shown on Fig. 2.

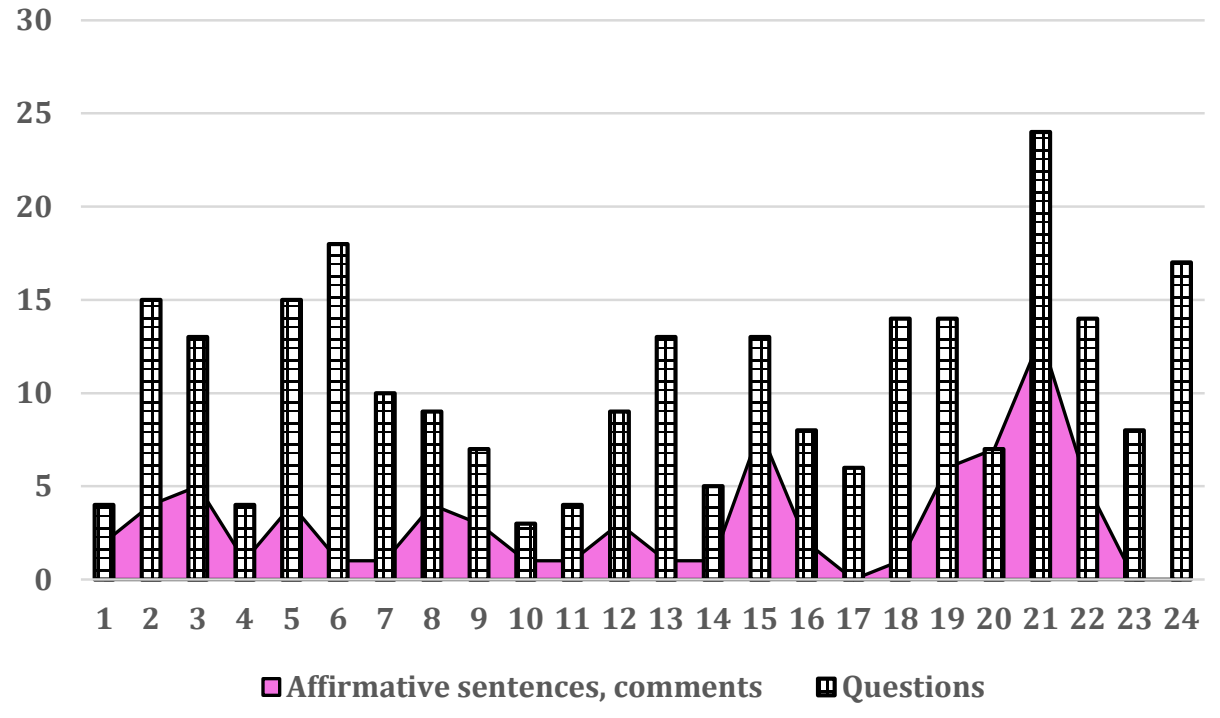

Figure 2. The correlation between declarative and interrogative sentences in the part of the text explaining the case task.

As it is evident from Fig. 2, the case studies contain a lot of clarifying information expressing value judgements of the text author. Actual questions are given only in two positions.

The task explanatory part contains the statements that impose certain reasoning on the learners. For example, the task of the case study "Wealth" includes such a statement: "Wealth and poverty should not be set in opposition, when the former is denounced and the latter is romanticized. It's also ridiculous to argue what's worth more to a person money and vast prospects it opens up, or spiritual integrity. Obviously, both!" (Savelyeva, 2013, p. 47). The content and the style of the text invite the reader to take a 
certain stance. Its content and style are oriented towards the adoption of a certain position.

The results of the content analysis suggest that the concept underlying construction of the teaching texts of the post-Soviet period, as compared to the teaching objectives of the Soviet period, is:

1) relatively similar in the part of the text giving the situation description;

2) is different in the part of the task explanation, which is related to introducing value judgements and providing the learners with additional information that can influence their decision.

Thus, it can be argued that in this part of the case there are significant differences in comparison with the composition and content of the task explanatory part of the teaching problems of the Soviet period. The tasks never contained explanations or judgments of the author. Therefore, adding to the text of the case study some declarative sentences which a priori contained value statements leading to certain judgments is an important novelty characterizing post-Soviet task explanation.

From our point of view, the proposed structural components of the case, are traditional; they do not inspire learners for cognitive and research activity. Case-study method is supposed to help students acquire unique authentic experience of solving complex professional problems, and alleviate the fears of handling unfamiliar tasks. The algorithm set in the Soviet case problems and preserved in the post-Soviet period does not develop an ability to assess the problem and work out the solution independently. The teaching objective of the case study is to provide a set of factual material for the analysis that can potentially lead students to their own position. The structure of the case study proposed in the article can be presented in several variants, where other approaches are equally welcome:

Variant 1. 1) Context of the case studied (occasion and / or precedent); 2) Participants' profiles; 3) Documented history of the event; 5) task for analytical summary; 6) outlooks of the problem solving - perspectives from the putsider and from the insider;

Variant 2. 1) Introduction (problem setting); 2) Problem (as seen by different participants of the event); 3) Materials necessary for solving the problem; 3) case solution scenarios; 
Variant 3. 1) The plot part (description of the situation, problem state etc.); 3) The information part (documents with factual information); 4) The method part (the task, that help students articulate their position and attitude to the situation) (Fedotova, 2007, p. 48-81).

What is in common for all three variants is the structural component directed at the presentation of factual documentation in its content (the third structural component of the variants listed). The case study following such plan can be titled with metaphors of the concept, like "Clinical record" or "Judicial case". As the case study method can be used in various training programs, we believe that the information part can be universally applicable in teaching different humanity subjects.

Let us briefly present the content of «Istanbul in the life and work of the artist M. Saryan». The theme was chosen as it is multidisciplinary and can be used teaching history, culture studies, art history, psychology, geography. It is rich in factual information, while the context of the case study and the case problem can be diverse. Martiros Saryan is a world-class artist whose work is a treasure of the Russian pre-Revolution and Soviet culture, as well as Armenian culture of the Soviet period.

The documental part of the case is represented by the following constituent parts:

1. Extracts from Saryan's autobiographical story «Out of my life» (Saryan, 1990) related to:

- the plans of his grandfather and the grandfather's brother to move to Constantinople (unlike those moving to Russian city of Nor-Nakhichevan) and their failed attempt to reach this city by sea (chapter "Nature-filled childhood");

- Saryan's trip to Constantinople in 1910 (chapter "Constantinople");

- the paintings created by the artist in Istanbul, and later purchased by Moscow arts patron in 1911 (chapter "Back to Moscow");

- the artist's impression of the sea voyage across Bosporus and the Sea of Marmara during his travel to Egypt (chapter "Travelling to Egypt");

- the paintings created in Paris and sent to Armenia through Istanbul in 1926 (chapter "Paris").

2. Reproductions of the paintings inspired by Saryan's travel to Turkey:

- The dogs of Constantinople. 1910. (See Fig. 3).

- Constantinople. 1910. 
- Constantinople street at midday. 1910.

- Constantinople. Dogs. 1910.

- Street. Constantinople. 1910.

- Wistaria. 1910.

- Still-life. Green jar and flower bouquet. 1910.

- Fruit shop. 1910.

- Still-life. 1910.

- Trees in blossom. 1910.

- Mules loaded with hay. 1910.

- Oriental merchants. 1910.

- Oriental women. 1910.

- Evening street. 1910.

- Lemonade monger. 1910.

- Flowers from Chamlych. 1910. (See Fig. 4).

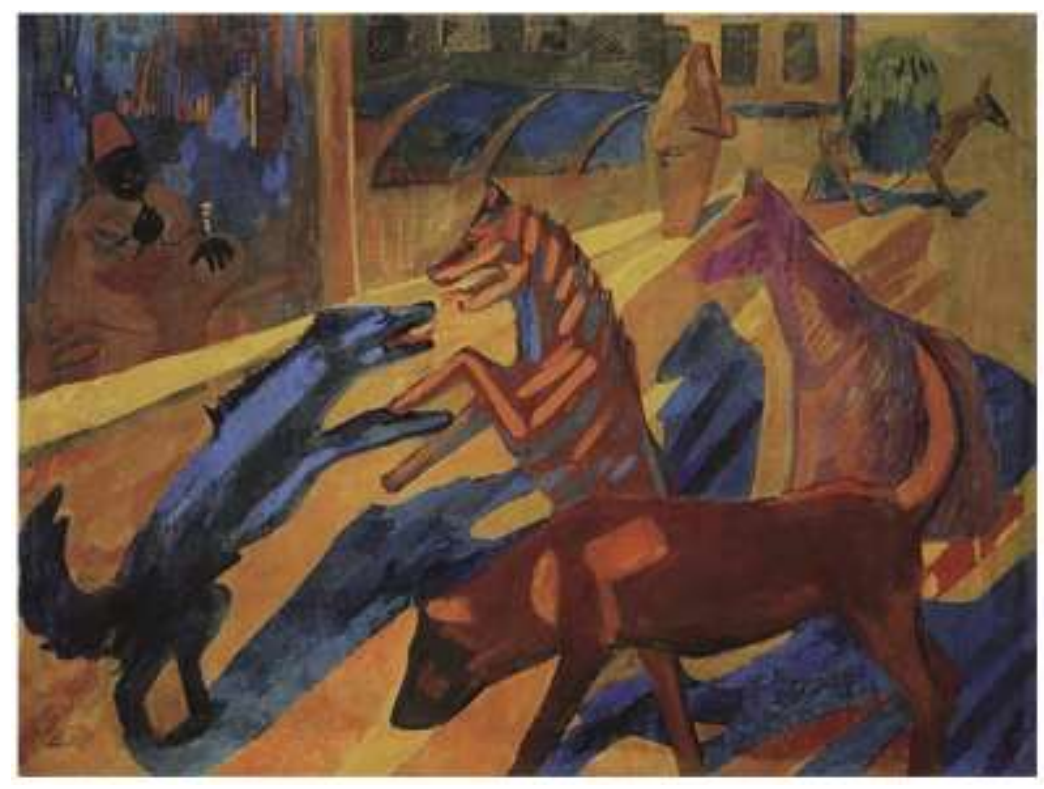

Figure 3. The dogs of Constantinople. 1910.

Note: The following figure is taken from Saryan (1990, p. 86). 
Fedotova et al.

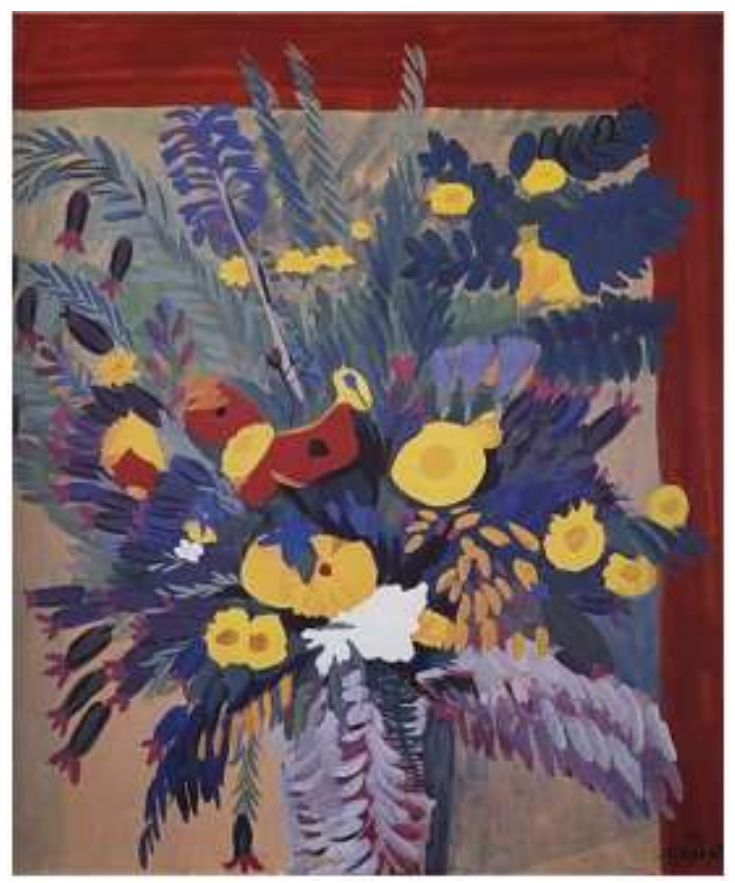

Figure 4. Flowers from Chamlych. 1910.

Note. The following figure is taken from Saryan (1990, p. 87).

3. Archive materials (the State Archives of the Rostov Region), photocopies of the following documents:

- Martiros Saryan's autobiography (1920), see Fig. 5;

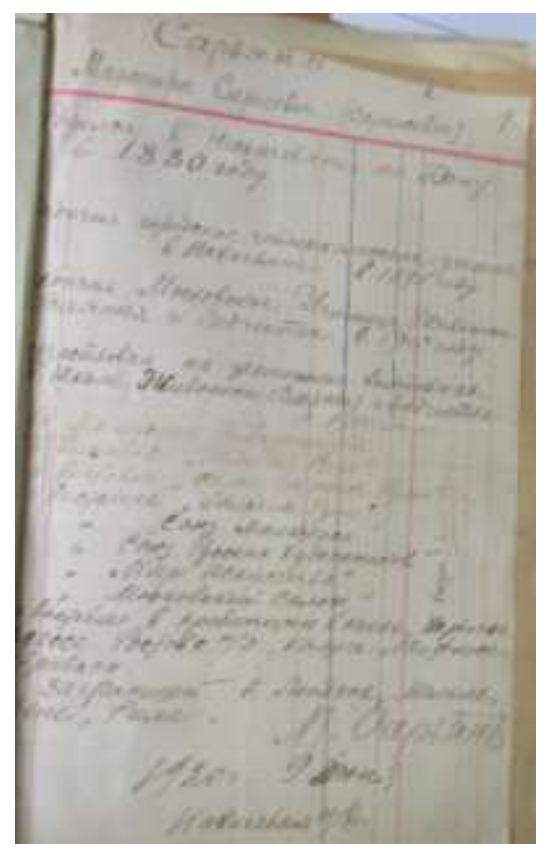

Figure. 5 Archival page from the autobiography of Martiros Saryan. 
Note. The following figure is taken from the State Archive of the Rostov Region. (1920).

- the minutes of the Culture Commission meetings (1920 - 1921) on establishing the Regional Armenian Museum in Rostov-on-Don.

4. Links to the electronic resources:

- https://ru.wikipedia.org/wiki/Сарьян,_Мартирос_Сергеевич

- http://sarian.am/index_eng.html

- https://www.britannica.com/biography/Martiros-Saryan

The problem of the case can be formulated in various ways depending on the discipline taught, e.g.:

History - The topic is "the Ottoman Empire (1299 - 1922)". The problem - names of two locations (Constantinople and Istanbul) used in the work of Saryan. The task - create a page from the historical-biographical atlas with the information of Saryan's stay in Turkey as it is shown in his paintings and autobiography.

Psychology. The topic is "The issue of national identity of an individual"/ The problem why Turkey-specific reality of Oriental culture is dominating in Saryan's pre-Soviet works over Russian culture, having in mind Russia was the country where the artist spent over 30 years of his life (1880-1921). The task - to analyze factual materials and to conduct content-analysis to prove what culture (European or Asian) Saryan was identifying himself with and how it is felt in his works.

Geography - The topic is "Global capital cities". The problem - what are the key geolocational and socio-economic factors for relocating the capital of the country farther inland? The tasks: - 1) give comparative analysis of the circumstances of the capital transfer from Petrograd to Moscow (1918) and from Istanbul to Ankara (1923); 2) having analyzed Saryan's itinerary in Turkey as it is seen from his works, design a geographic information mini project fill the geo information system with data on locations of objects timewise (as it 1910).

The ways of formulating case study structural components are outlined briefly in the article. They can be easily adjusted for other disciplines. Such approach has certain advantages: students learn to handle authentic documents which can help to feel the flair of the time period and show the peculiarities of its representation in various artistic forms. Learns can form their own opinions without being misled by the ready-made judgements. They are independent in 
Fedotova et al.

developing awareness of the problem in general and working out theoretical and practical aspects of possible solution of the problem.

\section{Conclusion}

The system of higher education is undergoing a challenging and multi-stage transfer from a "knowledge acquisition" paradigm focused on providing learners with ready-made knowledge, to the competence-based paradigm. The latter is targeted at professional functions and social performance in real-life conditions when problem-solving inevitably involves dealing with doubt and uncertainty.

As the study showed, the problem of teaching methods improvement is still relevant nowadays. Edifying and instructive teaching is giving way to the new methods, able to encourage cognitive activity of learners simulating actual working conditions of their professional activity. These include the method of solving the problems connected with particular situations, characteristics of which are historically specific. Situation-based teaching problems of the Soviet period were constructed around the ideas of foreign case studies. There were two components in their structure - description of the situation and the task. The trend continued into the post-Soviet period. According to the materials studied, there is a tendency to include many stance-imposing questions and statements. A different approach is proposed in the article. It can be titled "A court case" and contains a set of authentic documents presenting various aspects of the problem. The informative part is cross-functional and can be adjusted to different subject, while the task-explaining and final parts can reflect the specificity of the situation

The proposed structure of the case study has the advantage of offering not quite sufficient amount of information for those wishing to make a balanced judgement, in such a way encouraging learners to search for additional information relevant to the case. Thus, the learners develop their skills of fact analysis, comparison and classification. They learn to draw conclusions from the facts and master their creative approach in tackling professional issues.

\section{Acknowledgements}

The article was written within the framework of joint scientific project implemented by the scientists of Southern Federal University (Russian Federation) and Yerevan State University (Republic of Armenia) VN-Gr-07/2017-33 "Personality through the prism of history: features of 
Martiros Saryan's spiritual formation and creativity in the context of Russian and Armenian culture".

\section{References}

Aktan, S. (2016). How Can I Describe The Social Studies Curriculum? A Case Study. Journal of Social Studies Education, 7(1), 41-72.

Autobiography of Martiros Saryan. (1920). Fund 2577. Inventory 1. Unit of storage 9. Page 1.

Baumgartner, I. \& Shankararaman, V. (2015). Case studies in computing education:

Presentation, evaluation and assessment of four case study-based course design and delivery models. In: Proceedings - Frontiers in Education Conference, FIE-2015February, Paper 7044194.

Bovt, V.V. (2005). Modeling and instrumental support of online teaching technology for practical skills using case study method. PhD thesis abstract. Moscow.

Draskovic, M., Milica, D., Mladen, I., \& Chigisheva, O. (2017). Preference of institutional changes in social and economic development. Journal of International Studies, 10(2), 318328.

Egorova, E.V. (2008). Case study method in teaching strategic management in higher school. $\mathrm{PhD}$ thesis abstract. St. Petersburg.

Eliseev, D.A. (2010). Effectiveness increase of the independent work in the MChS Russian universities on the basis of virtual case technologies. $\mathrm{PhD}$ thesis abstract. St. Petersburg.

Fedotova, O.D. (2007). Innovative higher school and innovative school: sharp edges of interaction. In: Modern university - school: precedents and interaction phenomena. Tomsk: Publishing House of Tomsk University, 48-81.

Fedotova, O. \& Chigisheva, O. (2015). Comparative analysis: Methodological optics in the ideological context. International Perspectives on Education and Society, 26, 57-82.

Gadikurbanova, G.M. (2015). Case-technology in the formation of research competences of the future teacher invocational training. $\mathrm{PhD}$ thesis abstract. Makhachkala.

Hancock, D.R. (2006). Doing Case Study Research. New-York: Teachers College Press. Hedden, M.K., Worthy, R., Akins, E., Slinger-Friedman, V. \& Paul, R.C. (2017). Teaching sustainability using an active learning constructivist approach: Disciplinespecific case studies in higher education. Sustainability (Switzerland), 9(8),1320. 
Fedotova et al.

Kasitsky, I.Ya. (1948). Balance of the industrial enterprise and its analysis Collection of materials for tutorials. Moscow.

Kostryukova, L.A. (2006). Finance. The didactic complex (case) for students on specialty 080105 "Finance and credit". Study Guide. Chelyabinsk: Rekspol.

Krasikova, E.N. (2009). Case-method in the structure and content of the methodological competence of the linguist-teacher. PhD thesis abstract. Stavropol.

Kulyutkin, Yu.N. \& Sukhobskaya, G.S. (1981). Modeling pedagogical situations: Problems of improving general pedagogical training of a teacher. Moscow: Pedagogy.

Mauch, J. \& Tarman, B. (2016). A historical approach to social studies laboratory method. Research in Social Sciences and Technology, 1(2), 55-66.

Nadarajah, S., Bawden, R., Blackmore, C., Tidball, K.G. \& Wals, A.E.J. (2010). Resilience in learning systems: Case studies in university education. Environmental Education Research, 16(5-6), 559-573.

Naumova, E.V. (2014). Ethno-oriented language education at school and university with the use of case-method. PhD thesis. Kazan.

Saryan, M.S. (1990). From my life. Moscow: Fine Arts.

Savelyeva, M.G. (2013). Pedagogical cases: design and use in the process of teaching and assessing the competencies of students: Teaching and methodological manual. Izhevsk: Udmurt State University.

Shumova, I.V. (2010). The method of organizing and conducting pedagogical practice of the bachelor-philologist on the basis of case studies. PhD thesis abstract. Moscow.

Situational analysis or the anatomy of case study method. (2002). Textbook. Kiev: The Highest School.

Smolyaninova, G. (2000). Didactic possibilities of the case-study method in teaching students. URL: http://ipps.sfu-kras.ru/sites/ipps.institute.sfu-kras.ru/files/publications/53.pdf

Spirin, L.F., Frumkin, M.L. \& Pavlichkova, G.L. (1991). Pedagogical aims and their solutions. Moscow-Kostroma: MSCPI-KSPI named after N.A. Nekrasov.

The main production issues in the program of the initial party school of the mine. (1931). Methodical manual: For the circles and schools of the party enlightenment network. Rostov-on-Don: Northern Caucasus. 
Tulepbergenova, D.Yu. (2015). Development of intellectual activity of the student when using case-study in teaching a foreign language. $\mathrm{PhD}$ thesis. Makhachkala.

Tunstall, R. \& Lynch, M. (2010). The role of simulation case studies in enterprise education. Education and Training, 52(8), 624-642.

Vlasov, A.V. (2004). Econometrics. Basic concepts and formulas: a short course of case studies for correspondence students of specialties 060400 "Finance and credit". Balakovo, 2004.

Volostnikova, N.I. (2005a). Fundamentals of marketing: didactic case for students specialising in 061500 “Marketing”. Study guide. Chelyabinsk: Institute (branch) SEI HVE RSOTE.

Volostnikova, N.I. (2005b). Fundamentals of marketing: didactic case for students specialising in 351300 “Commerce (trade)”. Study guide. Chelyabinsk: Institute (branch) SEI HVE RSOTE.

Zubova, N.V. (2015). Complex case-technology for teaching physics as a means of forming basic professional competencies of students at the technical university. PhD thesis. Chelyabinsk. 